Chapman University

Chapman University Digital Commons

Psychology Faculty Articles and Research

Psychology

5-3-2019

Multiple Loves: The Effects of Attachment with Multiple Concurrent Romantic Partners on Relational Functioning

Amy C. Moors

William Ryan

William J. Chopik

Follow this and additional works at: https://digitalcommons.chapman.edu/psychology_articles

Part of the Gender and Sexuality Commons, Other Psychology Commons, Personality and $\underline{\text { Social Contexts Commons, and the Social Psychology Commons }}$ 


\section{Multiple Loves: The Effects of Attachment with Multiple Concurrent Romantic Partners on Relational Functioning}

\section{Comments}

NOTICE: this is the author's version of a work that was accepted for publication in Personality and Individual Differences. Changes resulting from the publishing process, such as peer review, editing, corrections, structural formatting, and other quality control mechanisms may not be reflected in this document. Changes may have been made to this work since it was submitted for publication. A definitive version was subsequently published in Personality and Individual Differences, volume 147, in 2019. DOI: 10.1016/j.paid.2019.04.023

The Creative Commons license below applies only to this version of the article.

\section{Creative Commons License}

\section{(c) 1 (1) 90}

This work is licensed under a Creative Commons Attribution-Noncommercial-No Derivative Works 4.0 License.

\section{Copyright}

Elsevier 
For final version see:

Moors, A. C., Ryan, W., \& Chopik, W. J. (2019). Multiple loves: The effects of attachment with multiple concurrent romantic partners on relational functioning. Personality and Individual Differences, 147, 102-110.

doi:10.1016/j.paid.2019.04.023

Multiple Loves: The Effects of Attachment with Multiple Concurrent Romantic Partners on Relational Functioning

Amy C. Moors ${ }^{1,2}$, William Ryan ${ }^{3}$, and William J. Chopik ${ }^{4}$

${ }^{1}$ Department of Psychology, Chapman University

${ }^{2}$ The Kinsey Institute, Indiana University, Bloomington

${ }^{3}$ Department of Psychology, University of Toronto

${ }^{4}$ Department of Psychology, Michigan State University

Correspondence concerning this article should be addressed to Amy C. Moors, Department of Psychology, Crean College of Health and Behavioral Science, Chapman University and The Kinsey Institute, Indiana University, Bloomington. Electronic mail may be sent to moors@chapman.edu. 


\begin{abstract}
In the present study, we sought to understand whether people in polyamorous relationships have similar attachment orientations with each of their partners. Further, we examined the extent to which the attachment relationship with a given partner affects relationship quality both within that relationship and across concurrent romantic relationships. We recruited a community sample of 357 people engaged in polyamory with at least two concurrent romantic partners. People engaged in polyamory exhibited secure attachment with both of their partners (low in avoidance and anxiety); specifically, these scores were lower than established norms. In terms of within-relationship effects, avoidance and anxiety with a specific partner were linked with lower levels of relationship functioning (relationship satisfaction, sexual satisfaction, satisfaction with emotional and sexual agreements, and commitment) for that specific relationship. However, there was no association between avoidance and anxiety with one specific partner and the relationship functioning in a different, concurrent romantic relationship (i.e., cross-relationship effects). These findings suggest that individuals engaged in polyamory treat these relationships as distinct and independent from one another-forming attachments with each partner based on the specifics of that relationship. Understanding attachment processes in polyamorous relationships provides new directions for exploring the diversities of intimate partnering and theory expansion.
\end{abstract}

Key words: consensual non-monogamy, polyamory, adult attachment theory, relationship quality, satisfaction 


\section{Multiple Loves: The Effects of Attachment with Multiple Concurrent Romantic Partners on Relational Functioning}

In society and in our science, we appear to view familial and platonic love as endless. We understand that we can give and receive love from multiple family members and friends. For instance, a parent does not "give all of their love" to their first-born leaving subsequent children without their parents' love. Similarly, many people report close friendships with multiple people (Demir, Özdemir, \& Weitekamp, 2007). Thus, it does not seem that love is limited to only one friend. Instead, loving multiple people in familial and platonic contexts is encouraged and deemed normal (Cicirelli, 1989; Volling \& Belsky, 1992). In the case of romantic love, however, it appears that we view this type of love as limited; romantic love is reserved for only one person. In Western society, people are expected to find their one soulmate (Day, Kay, Holmes, \& Napier, 2011; DePaulo \& Morris, 2005). Moreover, if people fall in love or lust for someone else, it is assumed that something must be wrong with them or their relationship (Burris, 2014; Moors, Matsick, Ziegler, Rubin, \& Conley, 2013).

Monogamy is (implicitly) assumed to be the healthiest form of romantic partnership by the general public (Conley, Matsick, Moors, \& Ziegler, 2017; Conley, Moors, Matsick, \& Ziegler, 2013; DePaulo \& Morris, 2005; Thompson, Bagley, \& Moore, 2018). That this promonogamy bias also extends to romantic relationship scientists (Moors, 2018), should not come as a surprise. Researchers are not immune to cultural norms and ideals of the societies in which they live. However, the assumption that dyadic partnering is universally optimal may have limited our understanding of intimate relationships, especially with regard to the complexities of attachment processes.

Many people practice serial monogamy (Fisher, 1989; Pinkerton \& Abramson, 1993). 
Although, a non-trivial number of people - approximately 21\% — have engaged in consensual non-monogamy at some point during their lives, and interest (via Internet queries) in these relationships has markedly increased over the past decade (Haupert, Gesselman, Moors, Fisher, \& Garcia, 2017; Moors, 2017). Consensual non-monogamous relationship arrangements involve people openly having more than one concurrent romantic and/or sexual partner (e.g., open relationships, swinging, and polyamory). Individuals engaged in multiple concurrent romantic and sexual relationships (referred to as polyamory) provides a unique opportunity to examine how attachment relationships with one partner may be related to relationship outcomes within a specific relationship as well as across concurrent relationships. As such, polyamorous relationships allow for novel theoretical testing of the bounds of attachment theory, a popular contemporary framework within romantic relationship science that has been almost exclusively applied to monogamous relationships.

\section{Attachment Theory and Multiple Loves}

More than 50 years ago, John Bowlby $(1969,1980)$ introduced attachment theory as a meta-theory for how relationships are organized across the life span by the attachment system. The attachment system directs emotion, cognition, and behavior in close relationships while regulating support seeking and provision during times of distress (Mikulincer \& Shaver, 2007; Shaver, Hazan, \& Bradshaw, 1988). Early life experiences with primary caregivers (attachment figures) calibrate this system, leading to dispositional differences in how individuals orient to relationships later in life (Fraley \& Shaver, 2000; Hazan \& Shaver, 1987).

Attachment orientation is thought to vary along two dimensions: anxiety (insecurity about a partner's availability) and avoidance (discomfort with closeness to a partner), which reflects the differences in sensitivity to relationship threats and the behavioral strategies employed to 
regulate attachment relationships (Cassidy, 2000; Fraley \& Shaver, 2000). Secure individuals score low on both dimensions, which reflects comfort with intimacy and interdependence. Attachment security is linked with stable relationships characterized by high commitment, satisfaction, and intimacy as well as low jealousy (Feeney, 2008).

Attachment theory posits that relational bonds with close others, especially romantic partners, are important sources of support, stability, and safety (Hazan \& Shaver, 1987). This theoretical framework for how people connect with others, particularly in romantic ways, does not appear to be specific to romantically and sexually exclusive relationships. Though, love and sexual exclusivity are often conflated among attachment theorists (e.g., DeWall et al., 2011; Hazan, Campa, \& Gur-Yaish, 2006). The present study seeks to answer three questions central to expanding attachment theory: (1) do people in polyamorous relationships have similar attachment orientations with each of their partners? (2) does the attachment relationship with a given partner affect relationship quality in that relationship (within-relationship effects)? and (3) does the attachment relationship with a given partner affect relationship quality in another concurrent romantic relationship (cross-relationship effects)? Below, we review relevant research while outlining hypotheses.

\section{Do people in polyamorous relationships have similar attachment orientations with}

each of their partners? Given research on consensually non-monogamous relationships is a small, but growing body of research, only one study (to our knowledge) has examined these relationships in the context of attachment (Moors, Conley, Edelstein, \& Chopik, 2015). Moors and colleagues (2015) examined how global attachment was related to hypothetical and actual engagement in a variety of consensually non-monogamous relationships. Among people who had never engaged in consensual non-monogamy, avoidant individuals desired consensual non- 
monogamy in the abstract sense (i.e., held positive attitudes and desire to engage in these relationships). However, when actual behavior was examined, a different pattern emerged. People engaged in consensually non-monogamous relationships reported lower levels of avoidance compared to people in monogamous relationships (anxiety levels were similar in both groups). Thus, people in consensually non-monogamous relationships exhibited aspects of global attachment security.

The question, remains, however, whether people have similar attachment orientations toward distinct partners they are dating simultaneously? On one hand, there is reason to expect that people with multiple concurrent romantic relationships would have similar attachment relationships with each of their respective partners. For instance, the connection between early attachment experiences and romantic attachment orientations in adulthood is well-documented (Feeney \& Noller, 1990; Fraley \& Roisman, 2015; Hazan \& Shaver, 1987). How people navigate their close relationships begins very early in life and these individual differences in attachment remain relatively stable across the lifespan (Chopik, Edelstein, \& Fraley, 2013). In conceptualizing how to measure attachment, the majority of researchers believe that an individual's orientation towards partners in general captures the "gist" of how people approach relationships (Fraley, 2007). Indeed, attachment orientations toward one person often predict outcomes in other domains, whether these outcomes are in relationships with other people or in non-relational domains altogether (Chopik et al., 2014; Gillath et al., 2005). There is also evidence that individuals' attachment orientations are consistent across sequential relationship partners (e.g., an ex-partner and current partner; Brumbaugh \& Fraley, 2007). Altogether, the studies reviewed thus far suggest that attachment orientations may be similar across partners. On the other hand, there is some evidence that individuals maintain attachment 
orientations for separate individuals simultaneously. This line of thinking posits that attachment orientations vary within people across various relationship partners (Baldwin, Keelan, Fehr, Enns, \& Koh-Rangarajoo, 1996; La Guardia, Ryan, Couchman, \& Deci, 2000). For example, Baldwin and colleagues (1996) found that individuals have multiple working models of relationships (often tied to different people), but these models vary in the ease with which they are activated. Thus, the working model of attachment employed at any given time is cued by the specifics of the relationship (Simpson, Rholes, \& Winterheld, 2010). Among attachment theorists, thinking about networks of close relationships has started to shift from a general framework to a relationship-specific framework. For example, in their validation of the Experiences in Close Relationships Structure measure, Fraley and colleagues (2011) found only little or moderate overlap in the attachment orientations individuals have for their mothers, fathers, romantic partners, and best friends. They also found that this relationship-specific approach is a stronger predictor of interpersonal outcomes than are global measures of attachment, a finding supported by previous research (e.g., Baldwin et al., 1996; La Guardia et al., 2000). Although it is difficult to directly draw comparisons between family members or friendships and multiple partners in the context of polyamory, it is plausible that the attachment relationship with each polyamorous partner may not be highly correlated. Thus, the present study examines the extent to which a person's attachment orientation with one romantic partner is related to their attachment orientation with another romantic partner who they are simultaneously dating.

\section{Does the attachment relationship with a given partner affect relationship quality}

within that relationship? Consistent with a large body of research on monogamous relationships, we anticipated that attachment orientations within a given relationship would function in theoretically consistent ways among people engaged in polyamory (see Cassidy, 
2000; Edelstein \& Shaver, 2004, for overviews). That is, we expected that people high in avoidance with a specific partner - those with tendencies to create psychological distance from partners — would report low levels of relationship quality in that specific relationship. Highly avoidant and anxious individuals experience low levels of relationship satisfaction, sexual satisfaction, and commitment (Birnbaum, 2007; Butzer \& Campbell, 2008; Davis et al., 2006; Kirkpatrick \& Hazan, 1994; Molero, Shaver, Fernandez, Alonso-Arbiol, \& Recio, 2016)—results we anticipated our findings to parallel at the within-person level. In other words, we do not have theoretical reasons to suggest that the associations between attachment orientations and relationship quality among people in polyamorous relationships would be inconsistent with previous research examining within-relationship dynamics.

\section{Does the attachment relationship with one partner affect relationship quality in} another relationship? Unlike studies examining attachment and family dynamics or friendships, polyamory — which places a focus on the ability to engage in multiple romantic relationshipsprovides a unique opportunity to test whether a deep romantic attachment bond with one person affects relationship quality with another person. For instance, if a person exhibits security with one partner, do the properties of this specific attachment relationship "spill-over" and influence their relationship quality with another partner? That is, if someone feels secure, connected, and happy with one partner, do these positive qualities "spill-over" and boost satisfaction in the person's other relationship? Or, if a person is highly anxious with one partner, does this specific attachment relationship negatively impact their relationship quality with another partner? Or, do people engaged in polyamory treat their relationships as independent?

Researchers have proposed three different ways in which consensually non-monogamous relationship partners may interact or cross-over with each other-additive, contrast, and 
compensation models (Mitchell, Bartholomew, \& Cobb, 2014; Muise, Laughton, Moors, \& Impett, 2017). One approach suggests that a high quality relationship with one partner could "spill over" and raise the quality of other relationships (an additive model), particularly if one of the relationships was faltering (a compensation model). Another approach suggests that love may be finite. Specifically, a low quality relationship with one partner could detract from relationship quality in another relationship (a contrast model). This type of transactional thinking is consistent with some of the investment model's conceptualization of rewards and costs in relationships (Rusbult, Martz, \& Agnew, 1998).

In testing these models, Mitchell and colleagues (2014) did not find support for any of the three models — additive, contrast, or compensation effects of partners — among people engaged in polyamory. Instead, people reported high need fulfillment (e.g., security, closeness, emotional support) and relationship quality (e.g., relationship satisfaction, commitment) in both of their concurrent relationships (Mitchell et al., 2014). In the context of sexual need fulfilment, Muise and colleagues (2017) did not find support for compensation or contrast effects among people engaged in consensual non-monogamy (including polyamory). Though, they did find support for an additive effect: high sexual need fulfillment was related to greater relationship satisfaction in another concurrent relationship (for men, this additive effect occurred across both of their relationships). In addition, there is qualitative evidence to suggest that people who are romantically in love with two partners describe each relationship as operating uniquely (albeit these individuals were not in consensually non-monogamous relationships; Jankowiak \& Gerth, 2012). Specifically, people cited different motivations, needs, and ways in which they felt love for each of their partners, suggesting that they were conceptualizing and treating each relationship as independent. Taken together, these studies suggest that various relationships held 
by people engaged in polyamory are largely treated as independent of each other and, in the case of sexual need fulfillment, there is an additive effect that positively influenced sexual quality across relationships.

Although the aforementioned models were originally conceptualized to examine need fulfilment across consensually non-monogamous relationships, these models can aptly be applied to understand how attachment orientations in one relationship affect functioning in another relationship. At a broader level, attachment is a predecessor to need fulfillment and orients people toward benefiting from close relationships. If a person is low on avoidance and anxiety (indicative of security) in one relationship, this could positively affect relationship quality in another relationship (supporting an additive model). Likewise, if a person is highly avoidant or anxious in one relationship, this could detract from relationship quality in another relationship (supporting a contrast model) or one secure relationship could compensate for another insecurely attached relationship (supporting a compensation model). However, consistent with the findings of Mitchell and colleagues (2014) and Muise and colleagues (2017), it is likely that we will not find robust support for any of the three models. That is, people engaged in polyamory may treat their relationships as independent and form attachments with each partner based on the specifics of that relationship.

\section{Present Study}

As outlined above, we sought to answer three questions: (1) do people in polyamorous relationships have similar attachment orientations with each of their partners? (2) does the attachment relationship with a given partner affect relationship quality in that relationship? and (3) does the attachment relationship with a given partner affect relationship quality in another concurrent romantic relationship? We recruited an online community sample of 357 people 
engaged polyamorous relationships, with at least two concurrent romantic partners [referred to in the following sections as P1 (partner \#1) and P2 (partner \#2)]. Participants reported on their attachment orientation to each of their partners, three dimensions of relationship quality with each of their partners, satisfaction with their current emotional and sexual relationship agreements with each partner, as well as various demographic characteristics. We hypothesized that within one relationship, higher levels of anxiety and avoidance would be associated with poorer relationship functioning. We also expected these associations to be specific to distinct relationships_-anxiety and avoidance with one relational partner will have little or no associations with relationship functioning in another relationship.

\section{Method}

\section{Participants and Sample Characteristics}

A community sample of participants was recruited online via social networking groups, listservs, and websites related to consensual non-monogamy (e.g., PolyWeekly). We contacted directors/webmasters of these CNM-specific websites/listservs and asked them to post advertisements for our study. Given consensually non-monogamous relationships are highly stigmatized (e.g., Moors et al., 2013), a targeted recruitment was required to obtain a large sample. Off- and on-line targeted recruitment has been successfully used by other researchers who study underrepresented populations, including sexual and racial minorities (e.g., Jellison, McConnell, \& Gabriel, 2004).

A total of 589 volunteer Internet respondents took part in the study. Because we were interested in attachment among individuals engaged in polyamory with at least two concurrent romantic partners, we excluded a total of 232 participants from our analyses who either: had a consensual non-monogamy agreement that did not allow for multiple romantic partners (e.g., 
swinging), did not have at least two concurrent romantic partners, or did not respond to the present study's variables of interest (e.g., attachment measures).

Thus, the final sample included 357 participants; 60\% identified as female, 29\% identified as male, $8 \%$ identified as gender queer/trans, and the remaining did not select a response. The majority of participants (79\%) identified P1 as their primary partner and P2 as a non-primary partner (72\%). On average, participants were dating P1 for 9.33 years $(S D=8.33)$ and P2 for 3.42 years $(S D=4.33)$. Forty-four percent of participants indicated that they were bisexual, 30\% identified as straight, 18\% identified as pansexual/queer, 3\% identified as gay or lesbian, and the remaining did not select a response. Breaking this down by gender, most women identified as bisexual (57\%) followed by pansexual/queer (20\%); most men identified as straight (63\%) followed by bisexual (28\%). These sizable portions of people who identified as nonheterosexual are consistent with national samples research in the U.S., which has documented that sexual minorities are more likely to have engaged in consensual non-monogamy than heterosexual people (Haupert et al., 2017). Our sample's racial/ethnic composition was 85\% white, 5\% multi-racial/ethnic, and the remaining were less than 1\% (each) African American, Asian/Pacific Islander, and Latino/a. Participants' age ranged from 18-77 years $(M=35.56, S D=$ 10.73). At $80 \%$ power (at $\alpha=.05$ ), our sample size enabled us to examine effects as small as $f^{2}$ $=.027$ and larger.

The majority of women respondents reported on two partners who were men; 81\% indicated their P1 identified as a man and 76\% indicated that their P2 identified as a man. Over half of women reported that their P1 identified as straight (56\%), followed by 34\% bisexual (the remaining were identified as either lesbian/gay or queer). Similarly, 52\% of women reported that their P2 identified as straight and 40\% identified as bisexual (the remaining were identified as 
either lesbian/gay or queer). The majority of men respondents reported on two female partners (93\% for P1 and 89\% for P2). Most men reported that their P1 identified as bisexual (68\%) followed by straight (28\%). Similarly, 65\% of men respondents reported that their P2 identified as bisexual and 31\% identified as straight (the remaining identified as either lesbian/gay or queer).

\section{Procedure and Measures}

Participants completed measures of relationship and sexual satisfaction, satisfaction with sexual and emotional agreements, commitment, and attachment for each of their current romantic partners (up to eight). To personalize the survey experience for participants (and to help avoid confusion), participants were asked to provide the initials for each partner and the items were tailored to include that partner's initials. For instance, when participants completed a measure of attachment for P1, they were responding to their specific levels of avoidance and anxiety with P1 (e.g., "It helps to turn to [P1's initials] in times of need").

Adult attachment. The Experiences in Close Relationships Inventory short version (12 items; ECR-S; Wei, Russell, Mallinckrodt, \& Vogel, 2007) was used to assess individual differences in adult attachment for each partner. The ECR-S avoidance subscale reflects discomfort with closeness. The anxiety subscale reflects concern about abandonment. Sample items include: "I try to avoid getting too close to [partner's initials]" (avoidance), and "I worry that [partner's initials] won't care about me as much as I care about them" (anxiety). Participants rated agreement with each statement using a 7-point Likert scale, ranging from 1 (disagree strongly) to 7 (agree strongly). For both partners, the avoidance subscale $\left(\alpha_{\mathrm{P} 1}=.84 ; \alpha_{\mathrm{P} 2}=.83\right)$ and anxiety subscale $\left(\alpha_{\mathrm{P} 1}=.72 ; \alpha_{\mathrm{P} 2}=.81\right)$ had high internal reliability.

Relationship satisfaction. Relationship satisfaction was assessed with the Couples 
Satisfaction Index Short form (CSI; Funk \& Rogge, 2007). The 16-item short CSI assesses global evaluations of romantic relationships and various scale anchors (e.g., agreement, frequency, semantic differentials). Higher scores indicated higher levels of satisfaction with a given partner. Sample items include: "In general, how often do you think that things between you and [partner's initials] are going well?" and "I have a warm and comfortable relationship with [partner's initials].” For both partners, these items demonstrated high internal consistency $\left(\alpha_{\mathrm{P} 1}=.95 ; \alpha_{\mathrm{P} 2}=.96\right)$.

Satisfaction with Relationship Agreements. To assess satisfaction with current relationship agreements regarding sex and emotional relations with each partner, we created two items. Participants rated their level of satisfaction with each statement using a 7-point Likert scale, ranging from 1 (not at all satisfied) to 7 (extremely satisfied). The items were: "How satisfied are you with the type of sexual agreement you and [partner's initials] have?" and "How satisfied are you with the type of romantic/emotional agreement you and [partner's initials] have?"

Sexual satisfaction. Sexual satisfaction was measured with the 20-item New Scale of Sexual Satisfaction (NSSS; Štulhofer, Buško, \& Brouillard, 2010). Participants were asked to rate their satisfaction with various aspects of their sex life during the last six months, including the quality of their orgasms, the pleasure they provide to their partner, the partner's sexual creativity, and the frequency of sexual activity. The NSSS ego-focused subscale (10-items) assesses self-sexual satisfaction and the partner- and sexual activity-centered subscale (10-items) assesses the sexual satisfaction derived from one's partner's sexual behaviors and diversity/frequency of sexual activities. Ego-focused subscale sample items include: "The quality of my orgasms" and "My emotional opening up in sex." Partner- and sexual activity-center 
subscale sample items include: “My partner's ability to orgasm” and "My partner's sexual creativity." For all items, participants responded with their level of satisfaction, using a 5-point scale, ranging from 1 (not at all satisfied) to 5 (extremely satisfied). Higher scores indicate greater sexual satisfaction. For both partners, the ego-focused subscale $\left(\alpha_{\mathrm{P} 1}=.93 ; \alpha_{\mathrm{P} 2}=.93\right)$ and the partner- and sexual activity-centered subscale $\left(\alpha_{\mathrm{P} 1}=.92 ; \alpha_{\mathrm{P} 2}=.90\right)$ had high internal consistency. Previous research has shown that the NSSS has demonstrated validity and reliability in non-clinical and different cultural samples (e.g., Štulhofer et al., 2010; Štulhofer et al., 2011). Given the strong correlation between the two subscales $\left(r_{\mathrm{p} 1}=.74\right.$ and $\left.r_{\mathrm{p} 2}=.70\right)$, we combined the subscales into one index of sexual satisfaction for each partner ${ }^{1}$.

Commitment. To assess relationship commitment and partner's perceived relationship commitment, we created a two-item measure. The items were: "How committed are you to this relationship?" and "In your opinion, how committed is your partner to this relationship?" Participants rated their commitment using a 7-point Likert scale ranging from 1 (not very committed) to 7 (very committed). For both partners, the two items were strongly correlated $\left(r_{\mathrm{p} 1}\right.$ $=.70$ and $\left.r_{\mathrm{p} 2}=.76\right)$, so we combined both items to assess commitment.

\section{Preliminary Results}

\section{Descriptive and Correlational Analyses}

Descriptive statistics and correlations among the five relationship functioning variables and attachment can be found in Tables 1 and 2. In general, participants reported high levels relational functioning with both partners. Within the relationship with P1, avoidance and anxiety were negatively related to all measures of relational functioning; correlations ranged from -0.18 to -0.65 , ps $<.001$. A similar pattern of results emerged with $\mathrm{P} 2$; correlations ranged from -0.17 to -0.70 , ps $<.001$ (with the exception that anxiety was marginally related to sexual satisfaction, 
$p=.07)$. Across the two relationships, avoidance was generally not related to cross-partner relational outcomes (only 1 out of the 10 cross-partner correlations was significant). Similarly, anxiety was generally not related to cross-partner relational outcomes (there was no relationship between P1 anxiety and P2 relational outcomes; however, three out of the five correlations with P2 anxiety and P1 relational outcomes were significant).

We also conducted a series of paired-samples $t$-tests to examine differences in relationship functioning between both partners. Participants reported greater relationship satisfaction, satisfaction with sexual and emotional agreements, and commitment to their relationship with $\mathrm{P} 1$ compared to $\mathrm{P} 2$, ts $(356)=4.62-13.35, d z s>.32$, $p \mathrm{~s}<.001$. However, participants reported more sexual satisfaction with $\mathrm{P} 2$ than $\mathrm{P} 1, t(304)=-2.20, d z=.18, p=.03(\mathrm{a}$ pattern of results consistent with recent research; see Balzarini et al., 2017).

\section{Main Results}

\section{Attachment Orientations across Partners}

\section{Do people in polyamorous relationships have similar attachment orientations with}

each of their partners? To simultaneously consider how attachment is related across partners (e.g., avoidance with P1 and P2) while controlling for the influence of the other attachment dimension (e.g., anxiety with P1), we conducted partial correlations (see Table 2 for Pearson correlations for comparison). Avoidance with P1 was positively related to avoidance with P2, when controlling for anxiety with P1 $[r(354)=.14, p<001]$ and controlling for anxiety with P2 $[r(354)=.16, p<001]$. Moreover, participants reported less avoidance with $\mathrm{P} 1$ than $\mathrm{P} 2, t(357)=$ $-10.89, d z=.75, p<.001$. A similar pattern of results emerged for anxiety, such that anxiety with P1 was positively related to anxiety with P2, when controlling for avoidance with P1 $r(354)$ $=.32, p<001]$ and controlling for avoidance with P2 [r(354) $=.30, p<001]$. Participants 
reported less anxiety with $\mathrm{P} 1$ than $\mathrm{P} 2, t(357)=-5.85, d z=.37, p<.001$.

On average, participants reported low levels of avoidance and anxiety with both of their partners $\left(M_{\text {avoidanceP1 }}=1.72, M_{\text {avoidanceP2 }}=2.49, M_{\text {anxietyP1 }}=2.61\right.$, and $\left.M_{\text {anxietyP2 }}=3.05\right)$; see Table 1. To contextualize these scores, we compared the present sample of polyamorous participants' means levels of avoidance and anxiety to established norms for the ECR-R (Fraley, 2019b; Fraley, Waller, \& Brennan, 2000; a comparable measure to the ECR-S used in the present study). Specifically, in an online sample of more than 17,000 people who completed the ECR-R, average scores for avoidance were $2.92(\mathrm{SD}=1.19)$ and anxiety were $3.56(\mathrm{SD}=1.12$; see Fraley, 2019b, for more details). Compared to established norms of avoidance, participants reported lower avoidance with both $\mathrm{P} 1$ and $\mathrm{P} 2, t(356)=-25.17, d=-1.33, p<.001$ and $t(356)=-$ 7.05, $d=-0.37, p<.001$, respectively. Similarly, participants reported lower anxiety, relative to established norms for anxiety, with P1 and P2, $t(356)=-17.15, d=-0.91, p<.001$ and $t(356)=-$ 7.11, $d=-0.39, p<.001$, respectively.

Taken together, people engaged in polyamory appear to orient themselves similarly_ and, securely — toward both of their romantic partners. Specifically, these results suggest that people engaged in polyamory exhibit relatively secure attachment in both of their concurrent relationships_-levels lower than established norms for avoidance and anxiety. These findings also extend previous research examining global (rather than partner-specific) attachment (Moors et al., 2015). Moreover, people reported lower levels of avoidance and anxiety with P1 compared to P2. Though, average scores for both attachment bonds were significantly lower than established norms (large general sample of adults).

Within- and Cross-Relationship Effects

To examine the extent to which avoidance and anxiety affect quality within a given 
relationship and across relationships, we conducted a series of parallel regression analyses, with the five measures of relationship functioning serving as dependent variables. In one analysis, outcomes for P1 are considered; in the second analysis, outcomes for P2 are considered. Given the number of analyses, we set the alpha at $p<.005$ (Bonferroni correction for ten regression analyses). Each regression model had two steps. On the first step, avoidance and anxiety (with the partner that matched the outcome) were entered as predictors of an outcome; on the second step, avoidance and anxiety (with the other partner) were entered as predictors of an outcome. We examined relationship length for both partners as a control variable. However, there was not a consistent pattern of significance for length of relationship for both partners across the measures of relational functioning (in the majority of cases, relationship length was not significantly related to the outcomes). Additionally, the pattern of results did not change when relationship length was removed from the analyses. Thus, lengths of both relationships were not included in subsequent analyses.

\section{Does the attachment relationship with a given partner affect relationship quality in}

that relationship? Our hypotheses were largely supported; across all five measures of relational functioning, avoidance with a given partner was negatively associated with relational functioning with that partner; see Tables 3 and 4. Specifically, highly avoidant individuals with P1 had lower levels of relationship satisfaction, sexual satisfaction, satisfaction with the type of romantic and emotional agreements, and commitment with P1. Similarly, results showed that highly avoidant individuals with P2 had lower levels of relational functioning (across all measures) with P2. Moreover, highly anxious individuals with P1 had lower levels of relationship satisfaction and satisfaction with the type of romantic and emotional agreements with P1. Results of the parallel analyses also show that anxiety with P2 was negatively associated with these three measures of 
relationship functioning with P2. Anxiety with a given partner (i.e., P1 or P2) was not related to sexual satisfaction with that partner. Avoidance and anxiety with P1 was negatively related to commitment with P1. However, parallel regression analyses show anxiety with P2 was unrelated to commitment to $\mathrm{P} 2$, but avoidance with $\mathrm{P} 2$ was negatively related to commitment to $\mathrm{P} 2$.

\section{Does the attachment relationship with a given partner affect relationship quality in}

another concurrent romantic relationship? As expected, for all five measures of relational functioning, avoidance and anxiety associated with one partner did not have cross-partner effects; see Tables 3 and 4. Specifically, avoidance and anxiety with P2 was unrelated to relational functioning with P1; parallel analyses also show that avoidance and anxiety with P1 was not related to relational functioning with P2. Thus, the attachment relationship with one partner does not affect relationship satisfaction, sexual satisfaction, satisfaction with the type of sexual and emotional agreements, or commitment with another partner.

\section{Discussion}

In the present study, we examined how attachment bonds among people with two concurrent romantic relationships are linked with relationship and sexual satisfaction, satisfaction with relationship agreements, and commitment. Specifically, we expanded the bounds of attachment theory in three novel ways by examining how attachment orientations were linked across partners as well as how attachment bonds affect relationship functioning within a specific relationship and across concurrent polyamorous relationships. First, we found that people engaged in polyamory tended to have similar orientations (both low in avoidance and anxiety) toward each of their two partners. In fact, the mean levels scores of avoidance and anxiety for both partners were lower than established norms for avoidance and anxiety (see Fraley, 2019b). Moreover, people in polyamorous relationships' attachment bonds were more 
secure with partner 1 (the partner they designated as "partner 1") than their secondary partner (although, both relationships would be considered secure). In general, people indicated that they were in a relationship with partner 1 for a greater period of time than partner 2 . Thus, it is not particularly surprising that people indicated greater attachment security with partner 1 (relative to partner 2), as attachment bonds tend to become more secure over time in a relationship (Davila, Karney, \& Bradbury, 1999). Taken together, these results provide some support for the notion that an individual's orientation towards partners, in general, captures the "gist" of how people similarly approach relationships (Brumbaugh \& Fraley, 2007; Fraley, 2007) as opposed to a relationship-specific framework of attachment (Fraley et al., 2011; La Guardia et al., 2000). Second, and as predicted, we found that relationship-specific attachment orientations predicted relationship-specific relationship outcomes. That is, higher levels of anxiety and avoidance were generally associated with lower relationship satisfaction, sexual satisfaction, commitment, and satisfaction with relational arrangements. These findings replicate and extend a large body of research on monogamous relationships (see Cassidy, 2000; Edelstein \& Shaver, 2004, for reviews) to the context of people with multiple concurrent romantic and sexual relationships. Finally, supporting our primary hypothesis, relationship-specific attachment orientations were unrelated to cross-relational outcomes - anxiety and avoidance with one partner was unrelated to relational outcomes in another concurrent relationship. Although people engaged in polyamory are stereotyped as having insecure and low quality relationships with motives to compensate for unmet needs (Burris, 2014; Conley et al., 2013), our results show that the attachment bond (which was generally secure) in one relationship did not influence relationship functioning with other partners. Thus, people engaged in polyamory treat their relationships as distinct and independent from one another, findings consistent with recent 
research that has not found support for additive, contrast, or compensatory models of relationship functioning among people with multiple concurrent partners (Mitchell et al., 2014; Muise et al., 2017).

The results of the present study provide insight for researchers interested in new directions related to attachment and consensual non-monogamy. For instance, these results provide some clarity to the ongoing debate about whether the development of a new attachment relationship weakens other relationships (see Fraley, 2019a, for an overview). In the case of polyamory, it appears that people can simultaneously be securely attachment to (at least) two romantic partners without influencing relationship quality across partners. Further, understanding how partners may be similar or how consensually non-monogamous change over time are fruitful avenues to better understand within and cross-relationship functioning among people engaged in consensual non-monogamy (see Chopik \& Kitayama, 2018; Eastwick, Harden, Shukusky, Morgan, \& Joel, 2017; Fraley, 2019a, for guidance). As such, we encourage researchers to consider changes in attachment and interest/engagement in consensually nonmonogamous relationships over-time, as a main limitation of the present study is the crosssectional design.

Moreover, research that could address how engagement in consensual non-monogamy may change an individual's attachment orientation would provide important insight into the malleability of the attachment system (see Arriaga, Kumashiro, Simpson, \& Overall, 2018, for a new model aimed at understanding how security may be enhanced). In a similar vein, Fraley (2019a) recently theorized that motivations to engage in consensual non-monogamy may be an important key to understanding the connection between attachment security and consensual nonmonogamy (as found in Moors et al., 2015 and the present study). For example, some people 
may seek out consensual non-monogamy because they want to dilute emotional closeness across multiple partners (avoidant individuals). However, other people may seek these relationship out because they want to embrace emotional and/or physical connections with multiple people (Moors, Matsick, \& Schechinger, 2017). According to Fraley (2019a) integrating similar scientific pursuits to understand attachment and motivations for sex (e.g., Birnbaum \& Reis, 2019) with engagement in consensual non-monogamy could be another promising avenue of inquiry.

In terms of the present study's recruitment strategy and design, we encourage future researchers to consider and, hopefully, address some limitations. Similar to other research on marginalized and/or hard-to-reach populations, we specifically targeted people via online communities focused on the topic (i.e., groups focused on consensual non-monogamy). As such, people engaged in such communities may have a well-integrated or positive sense of identity (as compared to people who are closeted or not involved in such community dialogue). Future researchers could consider broader recruitment strategies (albeit, labor intensive), such as recruiting people currently in a relationship and subsequently focusing only on those who are currently engaged in consensual non-monogamy. We also encourage researchers to examine how all members of a given consensually non-monogamous relationship view their relationships (e.g., satisfaction with given partners, metamour or friendship relationships). This approach would gain insight on actor-partner and/or network effects of attachment and relationship dynamics.

Taking an applied lens, the present study dovetails the recommendations by Schechinger and colleagues (2018), to examine relationship processes among people engaged in consensually non-monogamous relationships. As one applied example, Schechinger and colleagues found that a substantial number of therapists engaged in harmful practices with consensually non- 
monogamous clients, including lacking basic knowledge about non-monogamy and pushing clients to renounce their non-monogamous relationship. Thus, the results of the present studyand similar future endeavors that consider nuances of relationship functioning in consensually non-monogamous relationships_ — can be used in future trainings on diverse relationships for mental health care practitioners. 
Table 1

Means and Standard Deviations for Measures of Attachment and Relationship Quality

\begin{tabular}{lcccc} 
& \multicolumn{2}{c}{ Partner 1 (P1) } & \multicolumn{2}{c}{ Partner 2 (P2) } \\
\cline { 2 - 5 } Measures & Mean & SD & Mean & SD \\
\hline Avoidance & 1.72 & 0.90 & 2.49 & 1.15 \\
Anxiety & 2.61 & 1.04 & 3.05 & 1.35 \\
Relationship Satisfaction & 95.15 & 14.26 & 85.00 & 17.39 \\
Sexual Satisfaction & 3.80 & 0.88 & 3.93 & 0.82 \\
Satisfaction Sexual Agreement & 6.05 & 1.33 & 5.59 & 1.52 \\
Satisfaction Emotional Agreement & 6.25 & 1.06 & 5.51 & 1.50 \\
Commitment & 6.55 & 0.86 & 5.37 & 1.49 \\
\hline
\end{tabular}


Table 2

Correlations among Partner 1 and Partner 2 Attachment Orientations and Relational Functioning Variables

\begin{tabular}{|c|c|c|c|c|c|c|c|c|c|c|c|c|c|c|}
\hline & 1 & 2 & 3 & 4 & 5 & 6 & 7 & 8 & 9 & 10 & 11 & 12 & 13 & 14 \\
\hline 1. Avoidance P1 & -- & & & & & & & & & & & & & \\
\hline 2. Anxiety P1 & $.18^{* * *}$ & -- & & & & & & & & & & & & \\
\hline 3. Relationship Satisfaction P1 & $-.65^{* * *}$ & $-.25^{* * *}$ & -- & & & & & & & & & & & \\
\hline 4. Sexual Satisfaction P1 & $-.25^{* * *}$ & $-.18^{* * *}$ & $.51^{* * *}$ & -- & . & & & & & & & & & \\
\hline 5. Satisfaction Sexual Agreement P1 & $-.24^{* * *}$ & $-.23^{* * *}$ & $.52^{* * *}$ & $.51^{* * *}$ & -- & & & & & & & & & \\
\hline 6. Satisfaction Emotional Agreement P1 & $-.57^{* * *}$ & $-.26^{* * *}$ & $.72^{* * *}$ & $.33^{* * *}$ & $.50^{* * *}$ & -- & & & & & & & & \\
\hline 7. Commitment P1 & $-.57^{* * *}$ & $-.25^{* * *}$ & $.61^{* * *}$ & $.12^{*}$ & $.24^{* * *}$ & $.49^{* * *}$ & -- & & & & & & & \\
\hline 8. Avoidance P2 & $.16^{* *}$ & $.12^{*}$ & $-.15^{* *}$ & -.07 & -.03 & -.10 & -.04 & -- & & & & & & \\
\hline 9. Anxiety P2 & .01 & $.31^{* * *}$ & -.08 & $-.14^{*}$ & $-.15^{* *}$ & $-.13^{*}$ & -.05 & $-.22^{* *}$ & -- & & & & & \\
\hline 10. Relationship Satisfaction P2 & -.07 & -.08 & $.19^{* * *}$ & $.11^{*}$ & .10 & $.14^{* *}$ & .03 & $-.70^{* * *}$ & $-35^{* * *}$ & -- & & & & \\
\hline 11. Sexual Satisfaction P2 & -.10 & -.05 & .09 & .08 & .05 & $.15^{* *}$ & .02 & $-.32^{* * *}$ & -.10 & $.56^{* * *}$ & -- & & & \\
\hline 12. Satisfaction Sexual Agreement P2 & -.05 & -.03 & $.11^{*}$ & -.02 & $.13^{*}$ & $.20^{* * *}$ & .02 & $-.29^{* * *}$ & $-.22^{* * *}$ & $.58^{* * *}$ & $.57^{* * *}$ & -- & & \\
\hline 13. Satisfaction Emotional Agreement P2 & .004 & -.05 & $.11^{*}$ & .05 & $.11^{*}$ & .10 & .004 & $-.51^{* * *}$ & $-.39^{* * *}$ & $.72^{* * *}$ & $.38^{* * *}$ & $.55^{* * *}$ & -- & \\
\hline 14. Commitment P2 & -.08 & -.09 & $.14^{* *}$ & -.02 & .03 & .07 & .07 & $-.64^{* * *}$ & $-.17^{* *}$ & $.69^{* * *}$ & $.30^{* * *}$ & $.31^{* * *}$ & $.55^{* * *}$ & -- \\
\hline
\end{tabular}

Note. ${ }^{*} p<.05 .{ }^{* *} p<.01 .^{* * *} p<.001$. 
Table 3

Multiple Regression Analyses of Relational Quality and Agreement Outcomes for Partner 1 Predicted by Avoidance and Anxiety for

Partner 1 and 2

\begin{tabular}{|c|c|c|c|c|c|c|c|c|c|c|c|c|c|c|c|c|c|c|c|c|}
\hline \multirow[b]{2}{*}{ Predictors } & \multicolumn{4}{|c|}{ P1 Relationship Satisfaction ${ }^{\mathrm{a}}$} & \multicolumn{4}{|c|}{ P1 Sexual Satisfaction ${ }^{\mathrm{b}}$} & \multicolumn{4}{|c|}{$\begin{array}{l}\text { P1 Satisfaction with } \\
\text { Sexual Agreement }^{\mathrm{c}}\end{array}$} & \multicolumn{4}{|c|}{$\begin{array}{l}\text { P1 Satisfaction with } \\
\text { Emotional Agreement }^{\mathrm{d}}\end{array}$} & \multicolumn{4}{|c|}{$\mathrm{P} 1$ Commitment $^{\mathrm{e}}$} \\
\hline & $\mathrm{b}$ & $\mathrm{SE}$ & $\beta$ & $t$ & $\mathrm{~b}$ & $\mathrm{SE}$ & $\beta$ & $t$ & $\mathrm{~b}$ & SE & $\beta$ & $t$ & $\mathrm{~b}$ & $\mathrm{SE}$ & $\beta$ & $t$ & $\mathrm{~b}$ & SE & $\beta$ & $t$ \\
\hline \multicolumn{21}{|l|}{ Step 1} \\
\hline $\begin{array}{l}\text { Anxiety } \\
\text { P1 }\end{array}$ & -1.79 & .55 & -.13 & $-3.23^{* * *}$ & -.11 & .05 & -.13 & -2.44 & -.24 & .07 & -.19 & $-3.68^{* * *}$ & -.16 & .05 & -.16 & $-3.55^{* * *}$ & -.12 & .04 & -.14 & $-3.27^{* * *}$ \\
\hline $\begin{array}{l}\text { Avoidance } \\
\text { P1 }\end{array}$ & -9.88 & .64 & -.63 & $-15.42^{* * *}$ & -.22 & .05 & -.23 & $-4.21^{* * *}$ & -.29 & .08 & -.20 & $-3.86^{* * *}$ & -.63 & .05 & -.54 & $-12.30^{* * *}$ & -.52 & .04 & -.54 & $-12.44^{* * *}$ \\
\hline \multicolumn{21}{|l|}{ Step 2} \\
\hline $\begin{array}{l}\text { Anxiety } \\
\text { P1 }\end{array}$ & -1.61 & .59 & -.12 & $-2.75^{* * *}$ & -.08 & .05 & -.10 & -1.72 & -.20 & .07 & -.16 & $-2.93^{* * *}$ & -.13 & .05 & -.13 & $-2.82^{* * *}$ & -.12 & .04 & -.14 & $-3.10^{* * *}$ \\
\hline $\begin{array}{l}\text { Avoidance } \\
\text { P1 }\end{array}$ & -9.85 & .65 & -.62 & $-15.15^{* * *}$ & -.23 & .05 & -.23 & $-4.24^{* * *}$ & -.31 & .08 & -.21 & $-4.05^{* * *}$ & -.64 & .05 & -.55 & $-12.34^{* * *}$ & -.53 & .04 & -.56 & $-12.53^{* * *}$ \\
\hline $\begin{array}{l}\text { Anxiety } \\
\text { P2 }\end{array}$ & -.34 & .45 & -.03 & -.75 & -.07 & .04 & -.11 & -1.85 & -.11 & .05 & -.11 & -2.00 & -.07 & .04 & -.09 & -1.84 & -.01 & .03 & -.02 & -.46 \\
\hline $\begin{array}{l}\text { Avoidance } \\
\text { P2 }\end{array}$ & -.37 & .52 & -.03 & -.71 & .00 & .04 & .00 & -.01 & .05 & .06 & .04 & .83 & .02 & .04 & .02 & .47 & .05 & .03 & .07 & 1.57 \\
\hline
\end{tabular}

Overall model: ${ }^{\mathrm{a}} F(4,352)=69.33, p<.001 .{ }^{\mathrm{b}} F(4,326)=8.12, p<.001 .{ }^{\mathrm{c}} F(4,352)=9.86, p<.001 .{ }^{\mathrm{d}} F(4,352)=47.76, p<.001$.

${ }^{\mathrm{e}} F(4,352)=47.49, p<.001$.

Note. Bonferroni correction for tabled analyses ${ }^{* * *} p<.005$. 
Table 4

Multiple Regression Analyses of Relational Quality and Agreement Outcomes for Partner 2 Predicted by Avoidance and Anxiety for

Partner 1 and 2

\begin{tabular}{|c|c|c|c|c|c|c|c|c|c|c|c|c|c|c|c|c|c|c|c|c|}
\hline \multirow[b]{2}{*}{ Predictors } & \multicolumn{4}{|c|}{ P2 Relationship Satisfaction ${ }^{\mathrm{a}}$} & \multicolumn{4}{|c|}{ P2 Sexual Satisfaction ${ }^{\mathrm{b}}$} & \multicolumn{4}{|c|}{$\begin{array}{l}\text { P2 Satisfaction with } \\
\text { Sexual Agreement }\end{array}$} & \multicolumn{4}{|c|}{$\begin{array}{l}\text { P2 Satisfaction with } \\
\text { Emotional Agreement }^{\mathrm{d}}\end{array}$} & \multicolumn{4}{|c|}{$\mathrm{P} 2$ Commitment $^{\mathrm{e}}$} \\
\hline & $\mathrm{b}$ & $\mathrm{SE}$ & $\beta$ & $t$ & $\mathrm{~b}$ & $\mathrm{SE}$ & $\beta$ & $t$ & $\mathrm{~b}$ & SE & $\beta$ & $t$ & $\mathrm{~b}$ & $\mathrm{SE}$ & $\beta$ & $t$ & $\mathrm{~b}$ & $\mathrm{SE}$ & $\beta$ & $t$ \\
\hline \multicolumn{21}{|l|}{ Step 1} \\
\hline $\begin{array}{l}\text { Anxiety } \\
\text { P2 }\end{array}$ & -2.70 & .48 & -.21 & $-5.57^{* * *}$ & -.02 & .03 & -.03 & -.63 & -.18 & .06 & -.16 & $-3.16^{* * *}$ & -.33 & .05 & -.29 & $-6.59^{* * *}$ & -.03 & .05 & -.03 & -.72 \\
\hline $\begin{array}{l}\text { Avoidance } \\
\text { P2 }\end{array}$ & -9.86 & .57 & -.65 & $-17.29^{* * *}$ & -.23 & .04 & -.32 & $-5.89^{* * *}$ & -.34 & .07 & -.26 & $-5.02^{* * *}$ & -.57 & .06 & -.44 & $-9.90^{* * *}$ & -.82 & .06 & -.63 & $-15.01^{* * *}$ \\
\hline \multicolumn{21}{|l|}{ Step 2} \\
\hline $\begin{array}{l}\text { Anxiety } \\
\text { P2 }\end{array}$ & -2.93 & .51 & -.23 & $-5.77^{* * *}$ & -.02 & .03 & -.04 & -.67 & -.21 & .06 & -.18 & $-3.37^{* * *}$ & -.35 & .05 & -.32 & $-6.87^{* * *}$ & -.03 & .05 & -.03 & -.66 \\
\hline $\begin{array}{l}\text { Avoidance } \\
\text { P2 }\end{array}$ & -9.97 & .58 & -.66 & $-17.29^{* * *}$ & -.22 & .04 & -.31 & $-5.66^{* * *}$ & -.34 & .07 & -.26 & $-4.94^{* * *}$ & -.59 & .06 & -.45 & $-10.16^{* * *}$ & -.83 & .06 & -.63 & $-14.84^{* * *}$ \\
\hline $\begin{array}{l}\text { Anxiety } \\
\text { P1 }\end{array}$ & 1.02 & .65 & .06 & 1.57 & .01 & .04 & .01 & .18 & .09 & .08 & .03 & 1.18 & .13 & .07 & .09 & 1.96 & -.01 & .06 & -.01 & -.05 \\
\hline $\begin{array}{l}\text { Avoidance } \\
\text { P1 }\end{array}$ & .46 & .73 & .02 & .63 & -.05 & .05 & -.06 & -1.05 & -.04 & .09 & -.02 & -.45 & .10 & .07 & .06 & 1.35 & .02 & .07 & .01 & .34 \\
\hline
\end{tabular}

Overall model: ${ }^{\mathrm{a}} F(4,352)=99.37, p<.001 .{ }^{\mathrm{b}} F(4,322)=5.93, p<.001 .{ }^{\mathrm{c}} F(4,352)=11.45, p<.001 .{ }^{\mathrm{d}} F(4,352)=47.23, p<.001$.

${ }^{\mathrm{e}} F(4,352)=60.41, p<.001$.

Note. Bonferroni correction for tabled analyses ${ }^{* * *} p<.005$. 


\section{Footnotes}

1. A similar pattern of results emerged when the two subscales (self and partner sexual satisfaction) were analyzed as separate outcomes. 


\section{References}

Arriaga, X. B., Kumashiro, M., Simpson, J. A., \& Overall, N. C. (2018). Revising working models across time: Relationship situations that enhance attachment security. Personality and Social Psychology Review, 22(1), 71-96.

Baldwin, M. W., Keelan, J. P. R., Fehr, B., Enns, V., \& Koh-Rangarajoo, E. (1996). Socialcognitive conceptualization of attachment working models: Availability and accessibility effects. Journal of Personality and Social Psychology, 71(1), 94-109.

Balzarini, R. N., Campbell, L., Kohut, T., Holmes, B. M., Lehmiller, J. J., Harman, J. J., \& Atkins, N. (2017). Perceptions of primary and secondary relationships in polyamory. PloS one, 12(5), e0177841.

Birnbaum, G. E. (2007). Attachment orientations, sexual functioning, and relationship satisfaction in a community sample of women. Journal of Social and Personal Relationships, 24(1), 21-35.

Birnbaum, G. E., \& Reis, H. T. (2019). Evolved to be connected: The dynamics of attachment and sex over the course of romantic relationships. Current Opinion in Psychology, 25, $11-15$

Bowlby, J. (1969). Attachment and loss: Attachment (Vol. 1). New York: Basic Books.

Bowlby, J. (1980). Attachment and loss: Loss, sadness and depression (Vol. 3). New York: Basic Books.

Brumbaugh, C. C., \& Fraley, R. C. (2007). Transference of attachment patterns: How important relationships influence feelings toward novel people. Personal Relationships, 14(4), 513530. doi:doi:10.1111/j.1475-6811.2007.00169.x 
Burris, C. T. (2014). Torn between two lovers? Lay perceptions of polyamorous individuals. Psychology \& Sexuality, 5(3), 258-267.

Butzer, B., \& Campbell, L. (2008). Adult attachment, sexual satisfaction, and relationship satisfaction: A study of married couples. Personal Relationships, 15(1), 141-154.

Cassidy, J. (2000). Adult romantic attachments: A developmental perspective on individual differences. Review of General Psychology, 4(2), 111-131.

Chopik, W. J., Edelstein, R. S., \& Fraley, R. C. (2013). From the cradle to the grave: Age differences in attachment from early adulthood to old age. Journal of Personality, 81, 171-183. doi:10.1111/j.1467-6494.2012.00793.x

Chopik, W. J., Edelstein, R. S., van Anders, S. M., Wardecker, B. M., Shipman, E. L., \& Samples-Steele, C. R. (2014). Too close for comfort? Adult attachment and cuddling in romantic and parent-child relationships. Personality and Individual Differences, 69, 212216.

Chopik, W. J., \& Kitayama, S. (2018). Personality change across the life span: Insights from a cross - cultural, longitudinal study. Journal of Personality, 86(3), 508-521.

Cicirelli, V. G. (1989). Feelings of attachment to siblings and well-being in later life. Psychology and aging, 4(2), 211.

Conley, T. D., Matsick, J., Moors, A. C., \& Ziegler, A. (2017). The Investigation of consensually non-monogamous relationships: Theories, methods and new directions. Perspectives on Psychological Science, 12(2), 205-232.

Conley, T. D., Moors, A. C., Matsick, J. L., \& Ziegler, A. (2013). The fewer the merrier: Assessing stigma surrounding non-normative romantic relationships Analyses of Social Issues and Public Policy, 13(1), 1-30. 
Davila, J., Karney, B. R., \& Bradbury, T. N. (1999). Attachment change processes in the early years of marriage. Journal of Personality and Social Psychology, 76, 783-802.

Davis, D., Shaver, P. R., Widaman, K. F., Vernon, M. L., Follette, W. C., \& Beitz, K. (2006). "I can't get no satisfaction": Insecure attachment, inhibited sexual communication, and sexual dissatisfaction. Personal Relationships, 13(4), 465-483.

Day, M. V., Kay, A. C., Holmes, J. G., \& Napier, J. L. (2011). System justification and the defense of committed relationship ideology. Journal of Personality and Social Psychology, 101(2), 291-306.

Demir, M., Özdemir, M., \& Weitekamp, L. A. (2007). Looking to happy tomorrows with friends: Best and close friendships as they predict happiness. Journal of Happiness Studies, 8(2), 243-271.

DePaulo, B. M., \& Morris, W. L. (2005). Singles in society and in science. Psychological Inquiry, 16(2-3), 57-83.

DeWall, C. N., Lambert, N. M., Slotter, E. B., Pond Jr, R. S., Deckman, T., Finkel, E. J., . . . Fincham, F. D. (2011). So far away from one's partner, yet so close to romantic alternatives: Avoidant attachment, interest in alternatives, and infidelity. Journal of Personality and Social Psychology, 101(6), 1302-1316.

Eastwick, P. W., Harden, K. P., Shukusky, J. A., Morgan, T. A., \& Joel, S. (2017). Consistency and inconsistency among romantic partners over time. Journal of Personality and Social Psychology, 112(6), 838.

Edelstein, R. S., \& Shaver, P. R. (2004). Avoidant attachment: Exploration of an oxymoron. In D. Mashek \& A. Aron (Eds.), Handbook of Closeness and Intimacy (pp. 397-412). Mahwah, NJ: Lawrence Erlbaum. 
Feeney, J. A. (2008). Adult romantic attachment: Developments in the study of couple relationships. In J. Cassidy \& P. R. Shaver (Eds.), Handbook of Attachment: Theory, Research, and Clinical Applications (2nd ed., pp. 456-481). New York: Guilford Press.

Feeney, J. A., \& Noller, P. (1990). Attachment style as a predictor of adult romantic relationships. Journal of Personality and Social Psychology, 58(2), 281-291.

Fisher, H. E. (1989). Evolution of human serial pairbonding. American Journal of Physical Anthropology, 78(3), 331-354.

Fraley, R. C. (2007). A connectionist approach to the organization and continuity of working models of attachment. Journal of Personality, 75(6), 1157-1180. doi:10.1111/j.14676494.2007.00471.x

Fraley, R. C. (2019a). Attachment in adulthood: Recent developments, emerging debates, and future directions. Annual Review of Psychology, 70, 401-422.

Fraley, R. C. (2019b). Information on the experiences in close relationships-revised (ECR-R) adult attachment questionnaire. Updated July 23, 2005. Retrieved from http://labs.psychology.illinois.edu/ rcfraley/measures/ecrr.htm

Fraley, R. C., Heffernan, M. E., Vicary, A. M., \& Brumbaugh, C. C. (2011). The Experiences in Close Relationships_-Relationship Structures Questionnaire: A method for assessing attachment orientations across relationships. Psychological assessment, 23(3), 615.

Fraley, R. C., \& Roisman, G. I. (2015). Do early caregiving experiences leave an enduring or transient mark on developmental adaptation? Current Opinion in Psychology, 1, 101-106. doi:http://dx.doi.org/10.1016/j.copsyc.2014.11.007 
Fraley, R. C., \& Shaver, P. R. (2000). Adult romantic attachment: Theoretical developments, emerging controversies, and unanswered questions. Review of General Psychology, 4, 132-154.

Fraley, R. C., Waller, N. G., \& Brennan, K. A. (2000). An item response theory analysis of selfreport measures of adult attachment. Journal of Personality and Social Psychology, 78, 350-365.

Funk, J. L., \& Rogge, R. D. (2007). Testing the ruler with item response theory: increasing precision of measurement for relationship satisfaction with the Couples Satisfaction Index. Journal of Family Psychology, 21(4), 572.

Gillath, O., Shaver, P. R., Mikulincer, M., Nitzberg, R. E., Erez, A., \& Van Ijzendoorn, M. H. (2005). Attachment, caregiving, and volunteering: Placing volunteerism in an attachmenttheoretical framework. Personal Relationships, 12(4), 425-446.

Haupert, M. L., Gesselman, A. N., Moors, A. C., Fisher, H. E., \& Garcia, J. R. (2017). Prevalence of Experiences With Consensual Nonmonogamous Relationships: Findings From Two National Samples of Single Americans. Journal of Sex \& Marital Therapy, 43(5), 424-440.

Hazan, C., Campa, M., \& Gur-Yaish, N. (2006). What is adult attachment. In M. Mikulincer \& G. S. Goodman (Eds.), Dynamics of Romantic Love: Attachment, Caregiving, and Sex (pp. 47-70). New York, NY: Guildford Press.

Hazan, C., \& Shaver, P. R. (1987). Romantic love conceptualized as an attachment process. Journal of Personality and Social Psychology, 52(3), 511-524.

Jankowiak, W., \& Gerth, H. (2012). Can you love more than one person at the same time? A research report. Anthropologica, 54(1), 95-105. 
Jellison, W. A., McConnell, A. R., \& Gabriel, S. (2004). Implicit and explicit measures of sexual orientation attitudes: In group preferences and related behaviors and beliefs among gay and straight men. Personality and Social Psychology Bulletin, 30(5), 629-642.

Kirkpatrick, L. A., \& Hazan, C. (1994). Attachment styles and close relationships: A four-year prospective study. Personal Relationships, 1, 123-142.

La Guardia, J. G., Ryan, R. M., Couchman, C. E., \& Deci, E. L. (2000). Within-person variation in security of attachment: A self-determination theory perspective on attachment, need fulfillment, and well-being. Journal of Personality and Social Psychology, 79(3), 367384.

Mikulincer, M., \& Shaver, P. R. (2007). Boosting attachment security to promote mental health, prosocial values, and inter-group tolerance. Psychological Inquiry, 18(3), 139-156.

Mitchell, M. E., Bartholomew, K., \& Cobb, R. J. (2014). Need fulfillment in polyamorous relationships. The Journal of Sex Research, 51(3), 329-339.

Molero, F., Shaver, P. R., Fernandez, I., Alonso-Arbiol, I., \& Recio, P. (2016). Long - term partners' relationship satisfaction and their perceptions of each other's attachment insecurities. Personal Relationships, 23(1), 159-171.

Moors, A. C. (2017). Has the American public's interest in information related to relationships beyond "the couple" increased over time? Journal of Sex Research, 54(6), 677-684.

Moors, A. C. (2018). Moving past the rose-tinted lens of monogamy: Onward with critical selfexamination and (sexually) healthy science. Archives of Sexual Behavior, 1-5.

Moors, A. C., Conley, T. D., Edelstein, R. S., \& Chopik, W. J. (2015). Attached to monogamy? Avoidance predicts willingness to engage (but not actual engagement) in consensual nonmonogamy. Journal of Social and Personal Relationships, 32(2), 222-240. 
Moors, A. C., Matsick, J., \& Schechinger, H. (2017). Unique and shared relationship benefits of consensually non-monogamous and monogamous relationships: A review and insights for moving forward. European Psychologist, 22(1), 55-71.

Moors, A. C., Matsick, J. L., Ziegler, A., Rubin, J., \& Conley, T. D. (2013). Stigma toward individuals engaged in consensual non-monogamy: Robust and worthy of additional research. Analyses of Social Issues and Public Policy, 13(1), 52-69.

Muise, A., Laughton, A. K., Moors, A., \& Impett, E. A. (2017). Sexual need fulfillment and satisfaction in consensually nonmonogamous relationships. Journal of Social and Personal Relationships, 0265407518774638.

Pinkerton, S. D., \& Abramson, P. R. (1993). Evaluating the risks: A Bernoulli process model of HIV infection and risk reduction. Evaluation Review, 17(5), 504-528.

Rusbult, C. E., Martz, J. M., \& Agnew, C. R. (1998). The Investment Model Scale: Measuring commitment level, satisfaction level, quality of alternatives, and investment size. Personal Relationships, 5(4), 357-387. doi:10.1111/j.1475-6811.1998.tb00177.x

Schechinger, H., Sakaluk, J. K., \& Moors, A. C. (2018). Harmful and helpful therapy practices with consensually non-monogamous clients: Toward an inclusive framework. Journal of Consulting and Clinical Psychology, 86(11), 879-891.

Shaver, P. R., Hazan, C., \& Bradshaw, D. (1988). Love as attachment: The integration of three behavioral systems. In R. J. Sternberg \& B. M. L. (Eds.), The Psychology of Love (pp. 68-99). New Haven: CT: Yale University Press.

Simpson, J. A., Rholes, W. S., \& Winterheld, H. A. (2010). Attachment working models twist memories of relationship events. Psychological science, 21(2), 252-259. doi:10.1177/0956797609357175 
Štulhofer, A., Buško, V., \& Brouillard, P. (2010). Development and bicultural validation of the New Sexual Satisfaction Scale. Journal of Sex Research, 47(4), 257-268.

Štulhofer, A., Buško, V., Brouillard, P., Fisher, T., Davis, C., Yarber, W., \& Davis, S. (2011). The new sexual satisfaction scale and its short form. Handbook of sexuality-related measures, 530-532.

Thompson, A. E., Bagley, A. J., \& Moore, E. A. (2018). Young men and women's implicit attitudes towards consensually nonmonogamous relationships. Psychology \& Sexuality, 9(2), 117-131.

Volling, B. L., \& Belsky, J. (1992). The Contribution of mother - child and father - child relationships to the quality of sibling interaction: A longitudinal study. Child Development, 63(5), 1209-1222.

Wei, M., Russell, D. W., Mallinckrodt, B., \& Vogel, D. L. (2007). The experiences in close relationship scale (ECR)-short form: Reliability, validity, and factor structure. Journal of Personality Assessment, 88(2), 187-204. 